\title{
Electrical system resilience: a forensic analysis of the blackout in Lancaster
}

Paper for ICE: Forensic Engineering

Roger Kemp MBE FREng FRSA CEng FIET

Professorial Fellow, Lancaster University, UK

Contact address: New Engineering Building, Gillow Avenue, Lancaster University LA1 4YW

Email: $\underline{\text { r.kemp@lancaster.ac.uk }}$

\begin{abstract}
Britain's electricity network is undergoing a major transformation as it moves from a system based on burning fossil fuels in central power stations to one dominated by distributed renewable energy; this brings with it a new set of risks. In parallel, the move to electronic documentation and communication is increasing the dependence of society on an "always on" electricity supply. Assessing the level of dependence is difficult, as full-scale experimentation is not practicable and desk-top analysis of situations involving large numbers of human interactions are unlikely to be representative.

In December 2015, Storm Desmond resulted in a blackout affecting more than 100,000 people in Lancaster. This provided a unique case study that allowed researchers to investigate how society responds to widespread loss of the electricity supply.
\end{abstract}

Keywords: disaster engineering; energy; public policy.

\section{Introduction}

Civil society in the UK is dependent on a large number of infrastructure systems, including roads, railways, water supply, communications networks, the gas grid and electricity supply. Many of these are interconnected and the failure of one system can affect many others. At the same time as society's dependence on electricity has grown, the electricity supply network has become more indeterminate and with more complex failure modes. The model of the past 100 years of large central power stations feeding passive consumers is being replaced by complex networks where power can flow in any direction and with a diversity of sources of energy, many dependent on the time-of-day, the weather or the state of the tides. The introduction of smart meters and home energy management systems will further blur the boundary between the electrical power network and data/control systems and make Failure Mode and Effect Analysis (FEMA) increasingly difficult.

Over the first weekend in December 2015, Storm Desmond brought unprecedented flooding to North Lancashire and Cumbria, including to the industrial estate where Lancaster's main substation is located. At 22:39 hrs on Saturday, 5 December, electricity supplies to the city were cut. The loss of power quickly affected many other services that people take for granted. Most mobile phone coverage was lost and people who had replaced their traditional handsets with cordless phones were unable to connect. The internet was lost over most of Lancaster as were electronic payment systems, so shops were shut and ATMs (cash machines) did not work. The local TV booster station 
lost power, which also affected digital radio services. High-rise buildings in the city lost power for their lifts and some upper floors lost water supplies. Access control systems stopped working.

The effects on lighting, heating and cooking were predictable. The effects on communications, although foreseeable, took many people by surprise. Increasingly society has moved from paperbased to mobile phone and internet-based systems. The loss of these came as a shock to many people.

Storm Desmond provided a unique case study for forensic analysis of the growing dependence of society on an "always on" electricity supply. The effects of the loss of supply were discussed at a workshop, held on 9 March 2016 at Lancaster University, supported by representatives of many affected groups in the region. [RAEng 2016] This unplanned "full-scale experiment" provided an insight into the interdependence of infrastructure systems and has been closely followed by several government departments and other responsible bodies.

The direct cause of the loss of supply during Storm Desmond was a flooded substation. Since then, the flood barriers have been increased in height and the risks of a repeat event are greatly reduced. Other distribution network operators (DNOs) have also taken action to protect vulnerable distribution systems. However, there are many other potential causes for a widespread and prolonged loss of supply, including combinations of other effects of extreme weather, cyberterrorism and network issues. Of these, the last is probably the most difficult to quantify and this paper has concentrated on this, rather than on the more obvious issues of protecting distribution assets from rising water levels.

\section{The electricity supply network}

For 100 years, the principles behind Britain's electricity sector remained largely unchanged. The steam turbine was demonstrated by Sir Charles Parsons in 1884 and, before the First World War, Charles Merz had established the world's first ac distribution grid in Newcastle upon Tyne.

The last decade has seen the beginnings of a revolution: this is an international trend and one that will change the way established power systems operate. In Britain the Climate Change Act 2008 and similar regulations have triggered a paradigm shift in the way electricity will be produced. So far, there have been relatively small changes but phasing-out coal-fired power stations and the widespread adoption of renewable energy will change the power system radically. [IET 2014]

Power flows through the grid are also changing: rather than all power flowing from central power stations to passive consumers, electricity is being generated by solar PV panels on houses and businesses and by community scale renewable energy connected to the distribution grid. This can result in reversal of power flows that may not be within the capability of today's networks. There are also substantial new types of load coming on the system, including high-power chargers for plug-in vehicle batteries and electrically-powered heat pumps.

\section{Trends for GB electricity supply towards 2030}

In June 2016, the UK Government announced that is was accepting the Climate Change Committee's recommended Fifth Carbon Budget [CCC 2016] to reduce UK greenhouse gas emissions in 2030 by $57 \%$ relative to 1990 levels. This is compatible with the legal commitment to reduce emissions by at least $80 \%$ by 2050 . Because of the difficulty in reducing emissions from the transport and domestic heating sectors, the CCC envisages that the electricity supply system would be largely decarbonised by 2030 . 
Since November 2015, when UK funding for the development of carbon capture and storage (CCS) was cancelled, the main low-carbon sources of energy have been nuclear power and renewables. Of the present fleet of nuclear power stations, only Sizewell B is likely still to be in operation in the late 2020s. By then Hinkley Point $C$ should be operational and possibly one other new station, but these will not compensate for the $8 \mathrm{GW}$ of nuclear plant that will have been closed. Gas-fired power stations are likely to make a significant contribution over the coming decade but will have to be restricted to occasional use to meet the carbon budget.

Although there is not a formal target for the rate of new build of wind turbines, a study [RAEng, 2014] concluded that Britain could have about 26 GW of installed wind capacity by 2020 , split roughly equally between onshore and offshore, and $50 \mathrm{GW}$ by 2030, of which $30 \mathrm{GW}$ could be offshore and much of the rest in Scotland, some distance from the major loads on the network.

Solar energy is expected to make an increasingly important contribution to the GB network. In 2016, the installed capacity passed $10 \mathrm{GW}$ and, over the six summer months, solar energy produced almost 7 TWh. But for solar energy to provide significant support during periods of peak load, which are generally in the early evening in winter, it would have to be teamed with greatly increased energy storage.

\section{System effects of renewable energy}

Wind energy is one of the cheapest low-carbon energy sources. Wind varies from hour-to-hour and day-to-day but, over a year, the average output of a wind turbine is about one third of its peak output. As long as operators can be assured of a constant feed-in tariff, they can be fairly certain of their annual income.

From the system operator's perspective, the average can conceal important variations. Figure 1 shows the output of turbines connected to the GB grid during December 2008 and January 2009. For about 2 weeks at the end of January there was an anticyclone over much of Northern Europe resulting in negligible output from any GB wind turbine.

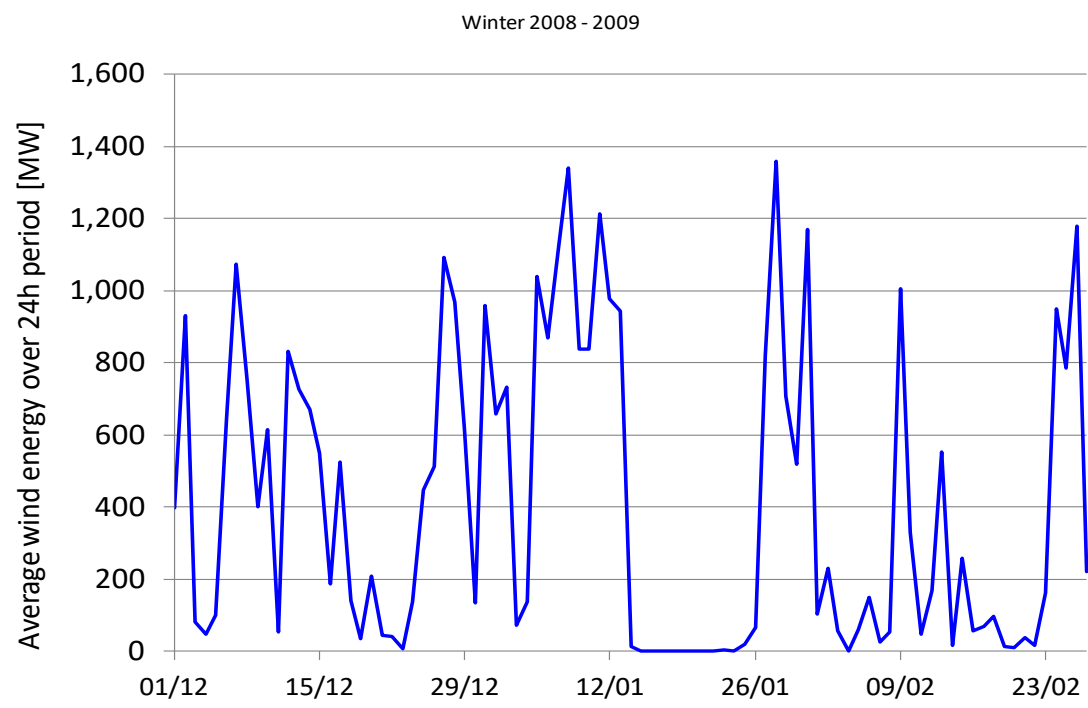

Figure 1: Data for grid-connected wind farms (source BM Reports)

It is unclear how climate change will affect wind energy; it seems likely that the jet stream will become weaker and more variable but climate scientists are not able to predict whether this will result in more long-duration windless periods. There has been no other period in the last decade comparable to January 2009 and it is improbable that any commercial business would consider 
holding fossil fuel power stations in reserve for a 2-week event every 10 years, unless very heavily subsidised.

Given the likelihood of periods of low wind when demand is high, it has been suggested that greater levels of interconnection to the Continent may be a solution as the wind is always blowing somewhere. However, analysis has shown significant correlation between wind in GB and in the rest of Northern Europe [RAEng 2014]. Figure 2, taken from the RAEng report, represents the correlation between wind output in Germany and GB. For 2012 and half of 2013, each hour is plotted as a point with the output from German wind farms on the $x$-axis and the output from GB farms on the $y$-axis. It can be seen that there are very few occasions where a low GB output was coincident with a high German output.

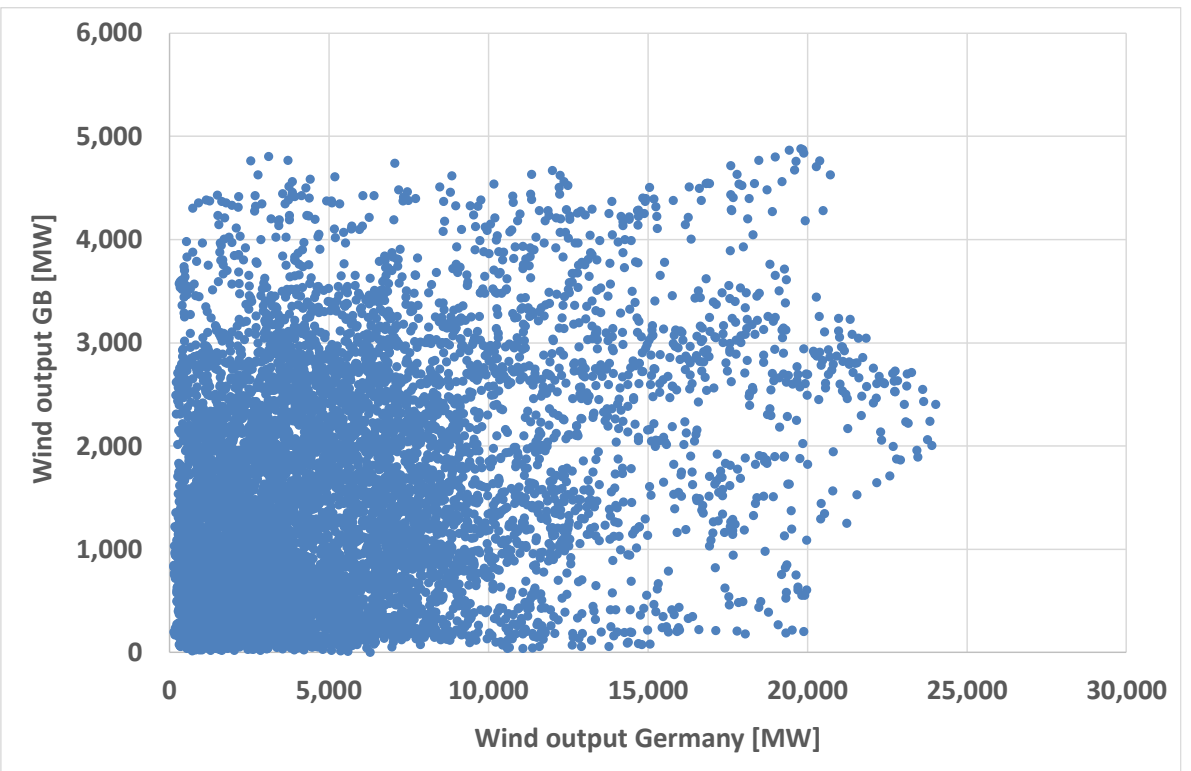

Figure 2: Correlation wind energy in Germany and GB

The present government has not published a strategy for solar energy but, in 2014, (what was then) the Department of Energy and Climate Change published a strategy to increase the amount of solar power to $20 \mathrm{GW}$ by 2023 and to concentrate this on medium/small installations which would feed into the LV or MV distribution systems, rather than into the high-voltage grid, like conventional power stations or "agricultural scale" solar farms. [DECC, 2014]. The load on the electricity system on a bright summer morning can be as low as $25 \mathrm{GW}$, which, by 2023 could be completely provided by solar panels and wind turbines.

Most commentators, including the British Infrastructure Group of MPs [BIG 2016], have concentrated on a potential mismatch between the available generation capacity and the expected load - the so-called "capacity margin". [RAEng 2013] However, this is unlikely to be the most critical issue. If the peak demand exceeds the supply capacity there is a range of actions the system operator can take from reducing the voltage, through pre-arranged disconnection of certain industrial loads, to a cycle of unannounced disconnections of some communities. As demand peaks last for only a few hours, this would be inconvenient but the occasional loss of power for a couple of hours would not be catastrophic.

However, there are several other potential problems in an electricity grid fed largely by renewables; two of these are discussed below:

Frequency stability: At present the system frequency is held at $50 \mathrm{~Hz}$ by large synchronous generators in coal, gas and nuclear stations. If the frequency increases (i.e. the turbines are running too fast), the flow of steam is reduced by the regulation systems, thus slowing the turbines, and vice 
versa. Wind turbines and solar panels lock onto this frequency but do not contribute to its stability. Experience in Ireland, which has a higher proportion of renewables than GB, is that the frequency tends to be less stable as the system has a much lower system inertia. [EirGrid 2012]

No country has yet run an electricity grid fed predominantly by renewables. In May 2016, Germany and Portugal operated for periods where all electricity consumption was matched by renewable generation but both are connected to the synchronous grid of Continental Europe (known as the Continental Synchronous Area) which included many synchronous generators that contributed to grid stability.

In GB, which has an independent grid, if the frequency goes outside the range 47 to $50.5 \mathrm{~Hz}$, protection systems on solar installations will automatically disconnect them from the network. And, if the frequency changes too quickly, there is the possibility of rate-of-change-of-frequency (ROCOF) protection relays operating. Either mechanism could result in a domino-effect shut-down of parts of the network.

Fault level: A second problem is caused by the way renewable energy is coupled to the grid. If there is a fault on a traditional network, the generators can provide a high short-circuit current (referred to as a high fault level) which causes circuit breakers to trip or fuses to blow to isolate the fault. Solar panels and many wind turbines are connected by inverters that are current-limited so a short circuit on a network fed predominantly by such sources could cause a collapse in the voltage but insufficient current to trip circuit breakers and isolate the fault. A high fault level is also important the operation of some dc transmission systems, such as the 2000 MW link between Sellindge in Kent and Calais, and many industrial drive systems.

It is clear that the way the electricity grid has been managed for the last 100 years is not suitable for the very different environment expected by the 2030s. A major study conducted by the Energy Systems Catapult and the Institution of Engineering and Technology (IET) has identified thirty-five new or significantly modified functions required to meet 2030 power system objectives. [IET 2016] This represents an unprecedented rate of change in the industry.

\section{Decarbonising heat and transport}

In round numbers, $30 \%$ of the UK's consumption of fossil fuels is used in the transport sector and $30 \%$ is used for low-grade heat - principally domestic and commercial space and water heating. In neither sector is carbon capture and storage likely to be possible. Thus, decarbonisation will rely on switching to renewable energy. Although hydrogen or biofuels could be an energy vector for some specialised areas, it is likely that electricity will be the vector of choice for most of that load. This will pose problems for the electricity system. A report by DECC considered the options for low-carbon heating [DECC 2013]. Figure 3 uses data from this report and plots the maximum half-hourly demand for each week in 2010. 


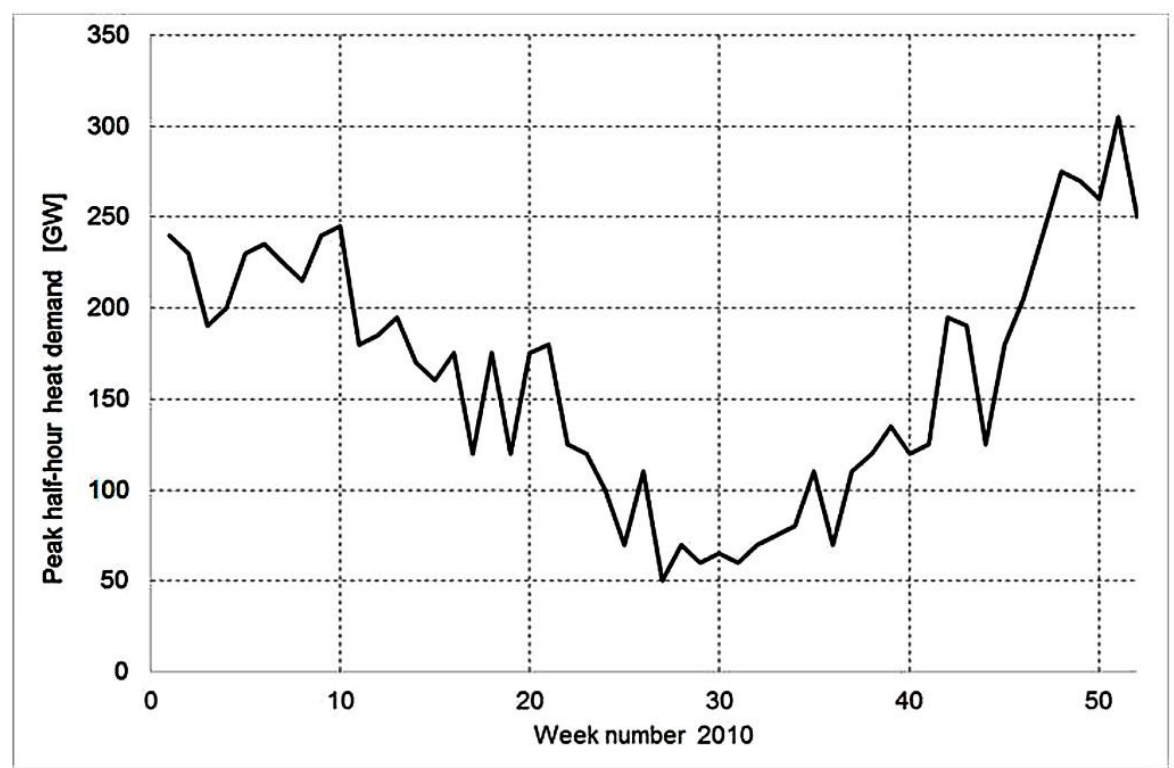

Figure 3: Peak half-hourly heat demand

While the peak demand on the GB electricity grid varies between 30 and $60 \mathrm{GW}$ over the year, the demand for heat can vary from almost nothing to $300 \mathrm{GW}$. If only half of this is provided by heat pumps with a coefficient of performance of 4 (i.e. one unit of electrical energy produces 4 units of heat), that represents an additional demand of $30 \mathrm{GW}$ in the winter compared with the summer. The overall demand could vary between about $25 \mathrm{GW}$ at off-peak times in the summer to $90 \mathrm{GW}$ at peak times in the winter.

The implications of this seasonal unbalance are profound. Up to now, investors in wind, solar PV or nuclear energy have been able to work on the assumption that there will always be a market for low-carbon electricity but, in the future, the low-carbon capacity needed to meet the winter peak could be much greater than the capacity that could be absorbed during the summer. Potential investors are thus likely to face a situation where substantial amounts of low-carbon electricity are needed only for the winter months. It is not obvious how the present market arrangements could make this an attractive proposition.

While widespread adoption of heat-pump systems will worsen seasonal and diurnal balance, the adoption of electric vehicles could improve the situation. A typical EV battery has a capacity of around $25 \mathrm{kWh}$; most vehicles will be only partially discharged during a normal day and thus will need to be charged every few days. However, if they are connected to a "smart" charger when not in use, the recharge can take place whenever there is spare generation capacity and can be terminated in the event of a sudden loss of generation [RAEng 2010]. More advanced schemes might also allow vehicle-to-grid (V2G) regeneration in which a charger is "put into reverse" if the grid frequency drops, thus regenerating some of the stored energy back into the grid. The downside is that such schemes would require sophisticated control systems which risk introducing more and complicated failure modes onto the system.

\section{The end of diversity?}

Traditionally, power supply authorities have considered consumers as having individual control over the load they take from the supply. Because of similar working hours and mealtimes, many households switch on lights, kettles and other equipment between 07:00 and 08:00 hrs and again between 16:30 and 17:30. However this increase in load can be represented by a large number of random events over the period, not a synchronised load increase. Supply companies rely on this 
diversity when calculating the necessary margins between supply and demand and in rating cables and other equipment.

Some of the most significant changes to the power system will be in the control individuals have over their electricity use. Consumers are beginning to see mobile phone apps that allow them to control their heating remotely; smart meters, which will be rolled-out over the coming five years, will be enablers that allow consumers to schedule electricity use; Google and Apple have announced plans for "smart homes" where heating systems and white goods respond to users' lifestyles, as part of the Internet of Things (IoT). Demand response takes place at the consumer level, but its impact when adopted at scale will affect the national as well as local power networks.

It is likely that "smart" consumer products, such as programmable electric vehicle (EV) chargers and adaptive thermostats, will have default settings. Unless householders delve into the menus and reset these defaults, there could be millions of consumers responding in an identical way to external stimuli, such as a change in a time-of-use tariff (TOUT). Of course, there have been synchronisation events before - the half time surge during cup finals is well known and "the kiss", to many signifying the end of the Royal Wedding broadcast in April 2011, caused a large load increase - but none had the impact of a million EV chargers taking load at the same time.

How systems from the large international technology companies will develop is unclear. Profits will be linked to the attractiveness of the products to consumers; whether they act as a stabilising or destabilising influence on the grid will be well down the order of priorities. In the future system operators could see conflicting nationwide systems influencing the electricity network: their actions to manage voltage and frequency conflicting with the herd effects of large groups of technology users with different objectives.

\section{Vulnerability of the network}

Previous sections have identified some of the potential vulnerabilities of the electricity network. Many of these are linked to the increasing complexity of the system, the number of active participants and the stochastic nature of many energy sources.

But, to date, the majority of blackouts have not been linked to network issues but to storm damage. After the loss of supply in Lancaster, commentators talked about a "once in a 100 years event"; however, the fundamental characteristic of climate change is that the present is - and the future will be - different from the past, so statements like this are meaningless. In the four months between November 2015 and March 2016, there were eleven named storms that affected the UK or Ireland: Abigail, Barney, Clodagh, Desmond, Eva, Frank, Gertrude, Henry, Imogen, Jake and Katie. All caused wind damage, flooding or both. Increasing climate volatility is likely to result in a greater frequency of events that could lead to loss of supply.

Intense storms are not the only possible natural cause of a blackout. Other natural causes include geomagnetic disturbances or solar flares. [RAEng 2013a] With increasing mutual dependencies between data systems and the electricity grid, electromagnetic disturbance to either is likely to have knock-on effects on the other system.

There are also man-made causes of a blackout; on 23 December 2015, more than 100,000 people in and around the Ukrainian city of Ivano-Frankivsk suffered a six-hour loss of power caused by cyberterrorism. A month later, the Israeli power system came under attack from hackers. Much of the UK's electricity infrastructure is in open country where protection from a determined and widespread physical attack would be almost impossible. 
With a diverse range of possible triggers for a loss of supply and growing dependency on other infrastructure and third-party control systems, it would be unreasonable to assume that blackouts can be "designed out" of the network. Although it is not possible to predict how they will be caused, society needs to plan for occasional periods when areas of the country will be without electricity. Key to this is an understanding of how the loss of supply affects other systems and social structures. This is why the events in Lancaster during Storm Desmond justify forensic analysis - they represent an unplanned experiment that could never have been intentionally undertaken. The following sections describe how different sectors of the community were affected by the events of December 2015 and provide lessons for managing future events, however they are triggered.

\section{Lancaster's experience}

On 5 December 2015, the Met Office issued a red severe weather warning for rain in Cumbria and North Lancashire. There had already been exceptional rainfall in Cumbria in the previous month; much of the ground was already waterlogged and the flood plain upstream of Lancaster was flooded. The River Lune, which runs past Lancaster's main electricity substation, rises to the north of the Howgill Fells in Cumbria and collects water from an area covered by the red warning, This catchment received more than $300 \mathrm{~mm}$ of rainfall during the storm. Normally the Lune is a quiet river (Figure 4) but, at peak, the Environment Agency recorded a flow of 1,742 cubic metres of water per second - the highest flow of any river ever recorded in England.

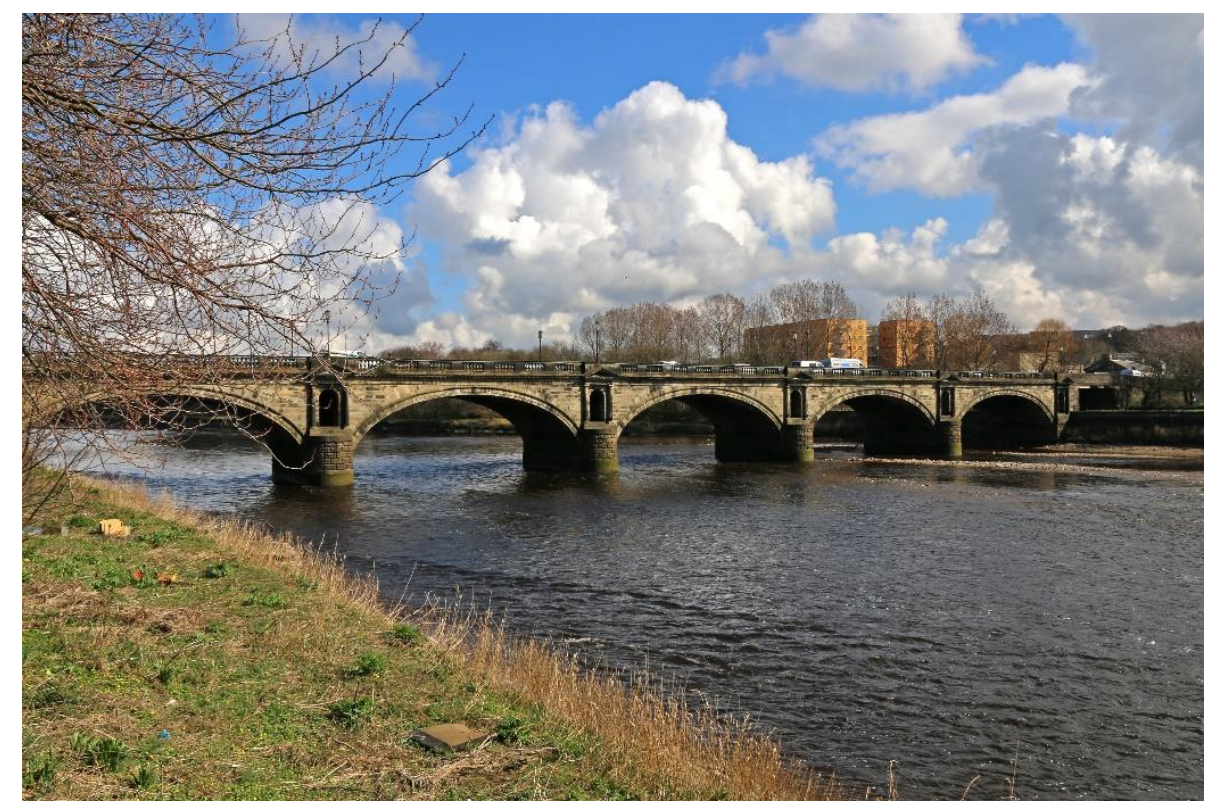

Figure 4: The River Lune

After flooding in recent years, the main Lancaster substation had been provided with a new flood barrier. For most of Saturday 5 December, the water level remained below the top of the barrier but, in the evening, it rose significantly and threatened to flood the substation. High-capacity pumps and additional protection were brought in but were unsuccessful. On-site representatives of Electricity North West (ENWL), the police and the fire service took the decision that, unless the substation was isolated, there was a risk of major damage and, at 22:39, the substation was switched off. Supplies were lost to 60,987 consumers. [RAEng 2016]

75 large generators were brought into Lancaster from as far away as the West Country and Northern Ireland and were hooked-up to local substations (Figure 5). These allowed 22,000 consumers to be reconnected during Sunday. By noon, the water had receded and the main substation had been 
pumped out, allowing safe access. Grid Transformer 1 was restored at 04:28 on Monday 7 December, which allowed supplies to many consumers by 15:30.

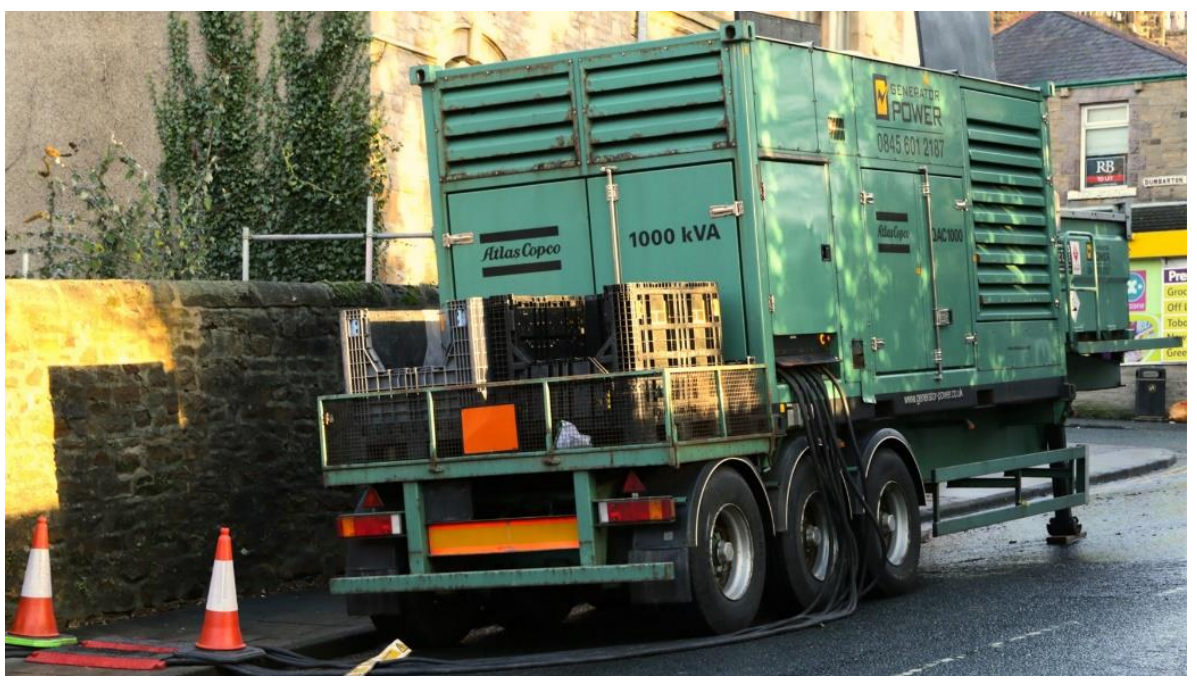

Figure 5: Portable generator

There were other problems later in the week where, during the flood, water had seeped into a highvoltage busbar chamber which subsequently caused a flashover. This was resolved by a major reconfiguration of the substation allowing all services to be restored by the end of the week.

\section{Communications}

The wired telephone system, powered from batteries in the exchange, continued to operate over most of Lancaster. Some areas were out of action but that was largely caused by flood water saturating the connection boxes, rather than the loss of electricity supply. Many people who had replaced wired handsets with wireless discovered that these do not work without a mains supply.

Mobile phone systems did not hold up. On most networks, the base station (the transmitter that provides the radio signal to communicate with phones in that area) is powered from the local $230 \mathrm{~V}$ electricity supply. Some have a battery back-up that continues to provide a service for an hour or two but few, if any, cope with the 30-hour loss or supply experienced over much of Lancaster. Inevitably, the loss of a mobile signal resulted in the inability to send or receive text messages or to use internet services.

Most domestic internet connections were also lost. This is because the equipment cases (Figure 6) that house the routers linking the high-speed fibre connections with the copper wires to individual houses are powered from the $230 \mathrm{~V}$ supply. 


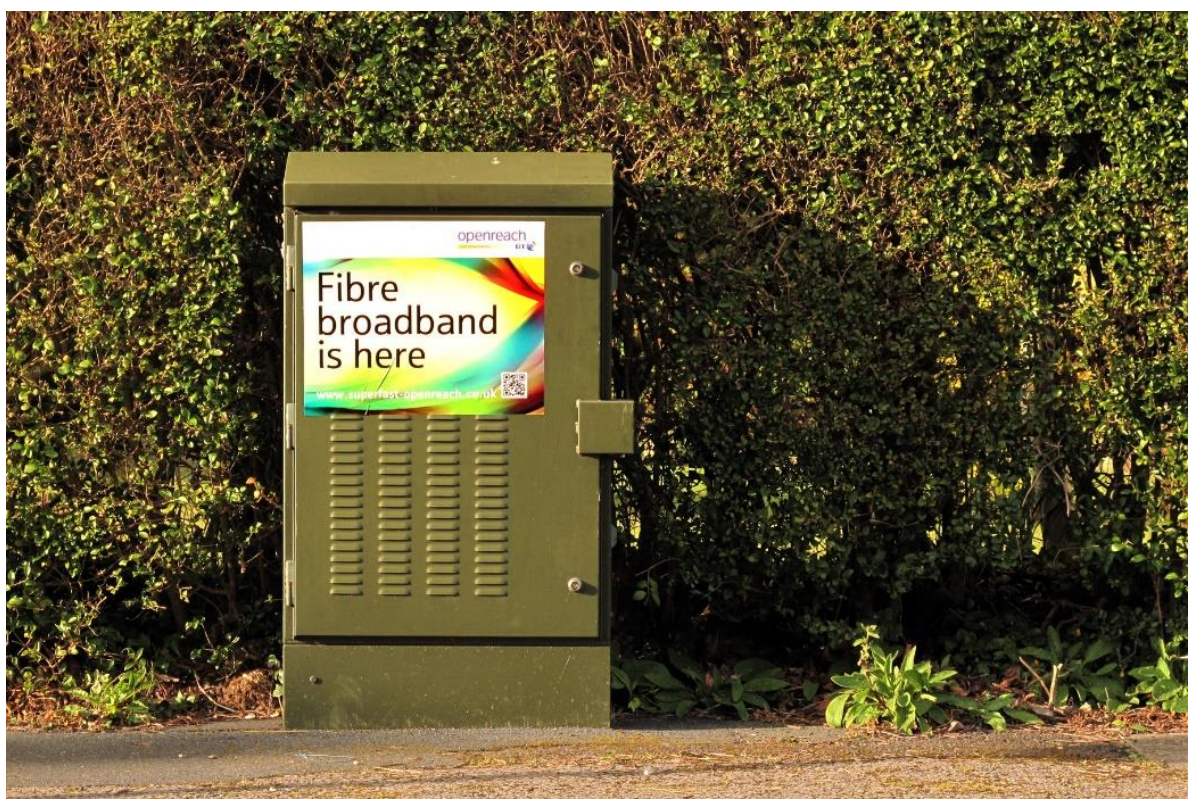

Figure 6: Broadband cabinet

During the floods and the loss of the electricity supply, local radio was the best way of finding out what was going on. The first challenge for many people was to find a battery or wind-up radio capable of receiving the FM band, as the local DAB radio transmitter was off-air. The second challenge was to find suitable batteries. The third was to decide which of the dozen or so FM channels available in Lancaster was most likely to include local news. On a traditional radio, of the sort one finds in the attic, there is no digital display of channel name and normally the only way to look up frequencies is to use the internet.

The most used channel was The Bay radio. Their studio is on the Quay overlooking the river. The ground floor flooded but they set up a temporary studio on an upper floor with a generator power supply. However, their only link with the outside world was via a single phone line. They sent one of their reporters home, to Heysham, which still had power, to look at the internet and phone in to say what she could find out that could be relayed to listeners. A second source of information came from listeners who phoned in with something interesting - useful snippets, such as where in Morecambe it was possible to get wireless internet reception or which roads were open. By contrast, some regional stations were based in other towns and, with no phone coverage, initially had no way of reporting what was going on.

\section{Effects on the University and schools}

Lancaster University has about 12,000 students, 7,000 of whom live on campus. During the 19841985 miners' strike, when the government cut back on electricity generation to conserve coal stocks and introduced rolling nationwide blackouts, students stayed in their rooms and used candles. Since then, health and safety standards have moved on. Candles are banned in rooms because of the fire risk; student residences have to be fitted with emergency lighting and smoke detectors.

Emergency lighting systems relying on batteries are designed to ride through a short interruption of supply or to give occupants time for an orderly and well-planned evacuation in the event of a more serious event. After about three hours, the batteries are exhausted. Fire alarm systems run for longer but often for less than a day. At 23:00 on Saturday, it was decided that the safest plan was to leave students in their accommodation, despite the lack of emergency lighting. 
Many students do not carry cash. Under normal circumstances, more than half of coffees and snacks bought on campus are paid for by a contactless card. With no electricity, there was no internet and thus cards did not work. The University decided to hand out free food, as did at least one restaurant in the city centre.

By 11:00 on Sunday, the news from the local network operator was that the power was likely to be off until Tuesday evening, so the decision was taken to close the university a week early. However, the usual way of communicating with students is email or a notice on the university website. With power supplies restricted to a few buildings, Wi-Fi was only available sporadically across the campus and many students' phones or tablets had flat batteries - so the university staff reverted to the more traditional technique of knocking on doors. Communicating with students living in flats in the city was more difficult and relied partly on face-to-face briefing of students on campus and hoping that they would pass on the message. Inevitably the message became corrupted: according to the police, a crowd of several hundred overseas students arrived at Lancaster police station expecting to find transport.

The situation was not made any easier by the closure of Lancaster railway station from dusk to dawn. Lancaster is on the West Coast Main Line (WCML) of the rail network. The WCML is electrified at $25 \mathrm{kV}$ but the power for trains in Lancaster is drawn from the $132 \mathrm{kV}$ lines at feeder stations near Garstang and Kendal, rather than from the local network. Thus, trains could continue to operate despite the loss of power in Lancaster.

Railway stations have auxiliary supplies taken from the local electricity network. These feed platform lighting, heating and lighting in offices and control rooms, de-icing heaters on points, the public address and information systems, ticket machines, lifts and other equipment. With the loss of the supply, all these stopped working. Without lighting or any of the normal means of communicating with passengers, the station operator took the decision to close at dusk.

Schools faced a different set of problems. At one time, there would have been a local education office familiar with problems "on the ground" but the Government's "academisation" policies have weakened this local link and head teachers found themselves on their own, with little local support. Unable to contact staff and with no more information than could be garnered from the local radio, most decided to close their schools for 3 days. Their next problems was how to communicate this decision to parents; the usual means was to use text messaging or emails, neither of which was available. Messages were broadcast by The Bay radio and by makeshift banners pinned to the school fence.

\section{Life in the city}

The problems at the university were merely part of a wider situation in the city. Cash machines and electronic tills in shops were not working; traffic lights and bus stops were dark; petrol pumps couldn't deliver fuel; electrically-operated garage doors wouldn't open; lifts stopped; swipe-card access systems didn't respond, and water supplies to upper floors of blocks of flats failed.

Investigations since the floods have identified that things could have been worse. The city's water supply is from a large reservoir in the hills, $100 \mathrm{~m}$ above the city, capable of storing thousands of tonnes of water. Had Lancaster relied on water towers, as do many other towns, the supply would not have lasted more than a few hours. The sewage system continued to cope without its usual source of power for pumps. Inhabitants were also lucky that the flood occurred on a Saturday evening; organisations, such as schools, had all Sunday to decide what to do. 


\section{The health service}

Like most district general hospitals, Lancaster Royal Infirmary has standby diesel generators. To allow for the possibility of generator failure, they are duplicated so that it had more generation capacity than it could use. It also has a fuel storage capacity for 14 days' use. Thus, the hospital should have been capable of carrying on as normal with no disruption to its operations.

However, the environment in which the hospital was operating was far from normal. The health service is structured so that a patient's first port of call is their GP, the 111 call centre or a pharmacy. Access to these was disrupted and so anyone seeking treatment or advice went to the hospital A\&E department, which quickly became overloaded. Because alternative service providers were unavailable, people phoned A\&E with minor questions, such as enquiring where they could obtain paracetamol. The hospital also received a large number of more serious requests, such as problems with home dialysis or to dispense repeat prescriptions as pharmacies were closed. The hospital pharmacy staff provided a good service under these conditions but nevertheless operated at significantly heightened demand.

More generally, the hospital was seen by many as a community centre. People with nowhere else to go wandered in off the street. The canteen served a record number of meals. A group of students arrived with a six-way extension lead and their mobile phone/tablet battery chargers which they connected to the first free 13A socket they could find. As a community centre, it was serving a valuable function - increasingly important as other facilities were closed - but well removed from its core business.

\section{People at risk}

Lancaster is a small city in a rural part of the country, For healthy people, with some spare cash and a full larder in their self-contained house, loss of power was not a serious problem. Those who had log-burners, camping cookers and a few bottles of wine in the cellar were able to invite neighbours round for an impromptu and convivial supper.

For some others, the experience was far less positive. One speaker at the university workshop [RAEng 2016] described the situation in a care home with 70 frail residents. The establishment lost light, heat, hot water, the ability to cook food, the phone system, call alarms, access control, electronic patient records, the power for hoists and other equipment and TV or other activities for the residents. Increasingly people with chronic illnesses are cared for in the community. Without electricity, dialysis or oxygen therapy machines did not work and the lack of stair lifts was restricting.

Luckily there are few high-rise flats as the failure of lifts, lighting, cooking, heating, water, intercom systems and access control would make life very difficult for the less mobile or for young families.

The situation for homeless people was particularly difficult. Being homeless in a city during winter is a difficult life. Being homeless in a city with no streetlights, no illuminated shop fronts and few people about is worse, causing unusual levels of fear and vulnerability. To some people, a mobile phone is still seen as a luxury; to many homeless people it is an essential. To contact the job centre or other official body, the choice is usually a phone call or, sometimes, email. A volunteer from a local community group, speaking at the workshop, described how the failure of communications was a serious loss to this group of people. 


\section{System resilience and complexity}

When considering the resilience of infrastructure systems, engineers have to take into account not only the system itself but how it is used. These are two aspects to resilience - what is the likelihood of failure under challenging conditions and what are the implications?

Thirty years ago, mobile phones were large and clunky; their users were often business executives for whom the phone was an optional tool and status symbol. Today whole groups of people do not have a traditional phone and a mobile is their main means of communication. Among the general public, 30 years ago computers were predominantly used by hobbyists, as replacements for calculators or as word processors. Web browsers had not been invented. In the intervening years, computers and the internet have become omnipresent. Paper-based and face-to-face systems have been phased-out and replaced by electronic data. Medical records, government documents, music purchase, meter readings, hospital appointments, newspapers, job applications, business meetings, photo albums, diaries, pharmaceutical prescriptions, address books, train timetables, phone directories, letters and applications for social benefits are all dependent on the internet.

The Department for Culture, Media and Sport has a policy for superfast broadband coverage to $95 \%$ of the UK by December 2017. The downside is that, the better the internet becomes, the more people will rely on it and the effects of the loss of the internet will quickly spread through the community. While the internet and mobile phones, which are central to Britain's way of life, rely on mains electricity, the effect on resilience of its loss are more severe.

The proliferation of electronic systems controlling the plethora of generating sources and controllable loads also introduces new risks due to increased complexity. Sidney Dekker has written "The growth in complexity in society has got ahead of our understanding of how complex systems work and fail. We are able to build things - from deep sea oil rigs to collateralised debt obligations whose properties we can model and understand in isolation. But, when released into competitive, nominally regulated societies, their connections proliferate, their interactions and interdependencies multiply. And we are caught short." [Dekker 2011]

In analysing the resilience of the electricity grid, engineers are not looking solely at one set of control systems owned by the system operator; they also have to consider the smart meter network and the way that electricity retailers and consumers will interact with them. "Smart" thermostats, EV battery chargers and heat pump control systems, the multitude of control systems associated with wind turbines and solar panels and the systems embedded in the Internet of Things (IoT) all impact electricity demand in some way.

The Major Project Authority is mainly concerned by the delivery and financial outturn of projects rather than by the detail of how the systems architecture is structured; however, there are remarkable parallels between the challenges identified by the MPA and by those identified by research into the way the grid is managed. [MPA, 2014] They have written "Given the number, complexity and scale of the challenges facing major projects, it is essential that we are realistic about what we can achieve, which means developing a culture of realism about these challenges. This kind of approach allows teams to find solutions before problems spiral out of control." The challenges identified by the MPA across a range of projects included technological complexity, new information technology, scale, multiple delivery partners and new organisational structures. These are the issues identified by research into the challenge of controlling the electricity system. 


\section{Where should resilience be located?}

Storm Desmond demonstrated the need for greater resilience in several systems on which people rely - in particular communications systems. This raises the question of where that additional resilience is best located. At one extreme, responsibility for coping with supply intermittency could be placed squarely on individual businesses and households - resilience is the responsibility of those affected. Such an approach of rugged self-reliance might send the message "If you rely on a mainspowered dialysis equipment, buy a petrol generator in case the power goes off". The downside to this policy is that those most at risk may be the ones least able to invest directly in effective resilience.

At the next level, it would be possible to place the responsibility on a service provider. For example, Ofcom could place a requirement in mobile phone operator licences that operators had to continue to provide a service under conditions of loss of power for at least 3 days. Alternatively, there could be a regulatory obligation on the distribution network operator (DNO) to provide duplication to maintain a supply of electricity under such circumstances.

Another option would be for regulators to allow a much greater rate of failures of the electricity supply and/or communications systems but to overlay this with a rapid-response mobile back-up system that could restore services on a temporary basis, while the main systems are being repaired. However, within the privatised telecoms sector and the diverse ownership of the internet, it is not clear where this responsibility should, or even could, reside.

It is not possible to choose one of the above strategies in isolation. Some, such as requiring mobile phone companies to maintain a service for several days without external power or requiring a DNO to hold $100 \%$ standby power for a large area, could be prohibitively expensive. The scope of emergency provision will depend on the scale of the disruption envisaged. ENWL had to scour the UK to find 75 generators to supply Lancaster; providing 750 to supply Birmingham would be a problem of a different order of magnitude. Coping with a four-day "black start" of the whole of Great Britain's electricity system would be another two orders of magnitude in scale.

The electricity supply system in Great Britain is generally very reliable. The Storm Desmond loss of power in Lancaster was noteworthy because of the number of people affected and the duration. Most consumers experience power cuts of no more than a few hours per year, if any. In cities like Lagos or Baghdad, where 12 hours of power cuts per day are not uncommon, it is not difficult for consumers to make a case for investing in standby generation. In Britain, few people would be prepared to pay for equipment that will be unused for years on end and may reach the end of its life without ever having been needed.

\section{Conclusions}

The importance of the resilience of the power system is related to how dependent society has become on "always on" electricity. The unplanned "experiment" of Storm Desmond suggests that it is central to society and is becoming increasingly important.

Decarbonisation of the electricity system could be seen to make it more resilient as it breaks the dependence on fossil fuels, most of which are imported and subject to political interruption. However, this form of dependence is being replaced by dependence on aspects of weather conditions that are themselves variable and will change unpredictably as a result of climate change. Over recent years, natural variability has been seen as more worrying than political interventions, but the situation could change. 
Increasingly, the electricity generating system is becoming dependent on the internet and intelligent systems. Some of these systems will be owned or managed by the system operator, others may be owned by technology companies with different objectives. Consumers could thus see a network of disruptive influences on the robustness of the electricity system - variable and unpredictable sources of energy, multiple owners, each attempting through complex software systems to optimise their corner of the system and possible interventions from hackers attempting to destabilise the network. This situation would be overseen by regulatory and management structures, based on market principles, that were designed for the last century.

Engineers are beginning to see well-researched technical solutions to reconfigure the network to make it suitable for its new role in a multi-player energy system and thus underwrite its resilience. Less well developed are possible replacements for the industry and regulatory structure. The lifetime of investments in energy systems are 25 to 50 years from initial concept to decommissioning. To ensure long-term resilience, it will be necessary to have new technical and management systems and structures in place well before 2030 - time is not on our side.

\section{Acknowledgements}

This paper is based on the contributions by the many speakers to the workshop at Lancaster University [RAEng 2016] and on research carried out by the author for the IET Power Networks Joint Vision project [IET 2014]. The support of many colleagues is gratefully acknowledged.

\section{References}

British Infrastructure Group: Electric Shock: Will the Christmas lights go out next winter, December 2016

Climate Change Committee, Fifth Carbon Budget, July 2016

https://www.theccc.org.uk/tag/5th-carbon-budget

Sidney Dekker: Drift into Failure - from hunting broken components to understanding complex systems. Ashgate, 2011. ISBN 978-1-4094-2222-8

Department of Energy and Climate Change (DECC): The Future of Heating: Meeting the challenge. March 2013

https://www.gov.uk/government/uploads/system/uploads/attachment data/file/190149/16 04DECC-The Future of Heating Accessible-10.pdf

DECC: Solar PV strategy - roadmap to a brighter future, updated March 2014.

https://www.gov.uk/government/publications/uk-solar-pv-strategy-part-1-roadmap-to-a-brighterfuture

EirGrid: Summary of Studies on Rate of Change of Frequency events on the All-Island System; August 2012 http://www.eirgrid.ie/site-files/library/EirGrid/Summary-of-Studies-on-Rate-of-Change-ofFrequency-events-on-the-All-Island-System.pdf

Energy Systems Catapult and the IET: The future power systems architecture project. July 2016, http://www.theiet.org/sectors/energy/resources/fpsa-project.cfm

Institution of Engineering and Technology: Transforming the electricity system - how other sectors have met the challenge of whole-system integration., October 2014.

http://www.theiet.org/factfiles/energy/pnjv-report-full-page.cfm 
Major Projects Authority: Annual Report 2013-2014, May 2014

https://www.gov.uk/government/publications/major-projects-authority-annual-report-2014

Royal Academy of Engineering, Electric Vehicles: charged with potential. ISBN 1-903496-56-X, March 2010 http://www.raeng.org.uk/publications/reports/electric-vehicles

Royal Academy of Engineering, Heat: degrees of comfort. ISBN 1-903496-77-2, January 2012 http://www.raeng.org.uk/publications/reports/heat-degrees-of-comfort

Royal Academy of Engineering: Extreme space weather - impacts on engineered systems and infrastructure, February 2013 ISBN 1-903496-95-0.

http://www.raeng.org.uk/publications/reports/space-weather-full-report

Royal Academy of Engineering: GB electricity capacity margin - a report for the Council for Science and Technology; October 2013.

http://www.raeng.org.uk/publications/reports/gb-electricity-capacity-margin

Royal Academy of Engineering: Wind energy - implications of large-scale deployment on the $G B$ electricity system; April 2014. ISBN: 978-1-909327-07-8

http://www.raeng.org.uk/publications/reports/wind-energy-implications-of-large-scale-deployment

Royal Academy of Engineering: Living without electricity - one city's experience of coping with loss of power: May 2016. ISBN 978-1-909327-26-9

http://www.raeng.org.uk/publications/reports/living-without-electricity

(All internet references accessed August 2016) 